\title{
EM BUSCA DA RESSIGNIFICAÇÃO DO ENSINO DE LÍNGUA INGLESA PARA OS ANOS INICIAIS DO ENSINO FUNDAMENTAL: RELATO DE EXPERIÊNCIA NA REDE MUNICIPAL DE EDUCAÇÃO DE NITERÓI ${ }^{24}$
}

\author{
IN SEARCH OF THE RESSIGNIFICATION OF ENGLISH LANGUAGE \\ TEACHING TO THE FIRST YEARS OF ELEMENTARY SCHOOL: REPORT OF \\ EXPERIENCE IN THE MUNICIPAL NITERÓI EDUCATION NETWORK
}

\author{
Jessica Fernandes N. da Cruz ${ }^{25}$
}

\begin{abstract}
Resumo
Este trabalho propõe a reflexão acerca do ensino de Língua Inglesa para os anos iniciais do Ensino Fundamental, no contexto da escola pública, em busca de um trabalho crítico com a linguagem e a formação cidadã. Por meio de um projeto interdisciplinar, a pesquisa teve como objetivo investigar o trabalho com gêneros discursivos multimodais, que permeiam as práticas de letramento sociais, utilizando a Internet como ferramenta de apoio pedagógico. A partir da aplicação de diversas atividades em uma turma do $5^{\circ}$ ano, uma foi selecionada e analisada com o propósito de observar o desenvolvimento da habilidade de compreensão leitora. Apesar da resistência e dificuldade com o Inglês, percebeu-se que o ensino da língua tem a possibilidade de ir além de frases isoladas e descontextualizadas.

Palavras-chave: Ensino de língua inglesa. Práticas de letramento. Novas tecnologias. Anos iniciais do ensino fundamental. Escola pública.
\end{abstract}

\begin{abstract}
This paper proposes a reflection about English Language teaching to the first years of Elementary Education, in the context of public school, in search of a critical language work and citizenship education. Through an interdisciplinary project, this research aimed to investigate the work with multimodal speech genres that permeate social literacy practices, using the Internet as an educational support tool. From the implementation of various activities in a group of the $5^{\text {th }}$ year of Elementary School, one was selected and analyzed in order to observe the development of the reading comprehension skill. Despite students' resistance and difficulty with some grammar structures, it was found that English may go beyond isolated and decontextualized language.
\end{abstract}

Keywords: English teaching. Literacy practices. New Technologies. Early years of elementary education. Public school.

\footnotetext{
${ }^{24}$ Pesquisa desenvolvida numa escola da Rede Municipal de Educação de Niterói, durante o Programa de Residência Docente, realizado por ocasião da Especialização em ensino de Língua Inglesa, cursada no Colégio Pedro II, na cidade do Rio de Janeiro.

${ }^{25}$ Mestranda do Programa de Pós-graduação de Ensino em Educação Básica (CAp-UERJ), com ênfase no ensino de Língua Inglesa, especialista em docência da Língua Inglesa pelo Programa de Residência Docente (2016) do Colégio Pedro II e licenciada em Letras, Inglês e Literaturas, pela Universidade do Estado do Rio de Janeiro (2015). Atualmente, atua como professora dos anos iniciais do Ensino Fundamental na Fundação Municipal de Educação de Niterói. E-mail: jenatarelli@gmail.com
} 


\section{Considerações iniciais}

O ensino de Língua Inglesa expandiu-se para os primeiros anos do Ensino Fundamental, nas principais redes municipais de ensino do Estado do Rio de Janeiro. Anteriormente, o idioma somente era ofertado a partir do $6^{\circ}$ ano do Ensino Fundamental, assim como determina a Lei de Diretrizes e Bases da Educação Nacional (BRASIL, Lei 9394/96, art. 26, §5%).

Acredita-se, a escolha do Inglês deve-se ao fato da participação do Brasil em diversos eventos internacionais e da necessidade de atender às demandas sociais que fazem uso do idioma. Além disso, segundo Pennycook (1998), a expansão hegemônica da Língua Inglesa tem origem histórica no papel da Inglaterra como potência colonizadora e no poder econômico dos Estados Unidos, refletindo na presença do crescimento de tecnologias e corporações multinacionais.

O caso típico é o papel representado pelo Inglês, em função do poder e da influência da economia norte-americana. Essa influência cresceu ao longo deste século, principalmente a partir da Segunda Guerra Mundial, e atingiu seu apogeu na chamada sociedade globalizada e de alto nível tecnológico, em que alguns indivíduos vivem neste final do século. O Inglês, hoje, é a língua mais usada no mundo dos negócios, e em alguns países, como Holanda, Suécia e Finlândia, seu domínio é praticamente universal nas universidades. É possível antever que, no futuro, outras línguas desempenhem esse papel (BRASIL, PCNs de Língua Estrangeira, 1998, p. 23).

Portanto, entende-se que há necessidade de ofertar o ensino de Inglês de maneira a proporcionar uma formação capaz de desenvolver habilidades para que o aluno se torne também cidadão do mundo. Ademais, de acordo com Moita Lopes (1996) e com Brasil (1998), o aprendizado de uma Língua Estrangeira é relevante à medida que contribui para o desenvolvimento da Língua Materna e leva ao aluno a 
refletir sobre a sua própria cultura, ao expandir os seus horizontes linguísticos por meio do contato com outras culturas e com outras formas de ver o mundo. Assim sendo, aprender uma Língua Estrangeira é muito mais do que assimilar um conjunto de habilidades linguísticas, considerando que ela

[...] leva a uma nova percepção da natureza da linguagem, aumenta a compreensão de como a linguagem funciona e desenvolve maior consciência do funcionamento da própria língua materna. Ao mesmo tempo, ao promover uma apreciação dos costumes e valores de outras culturas, contribui para desenvolver a percepção da própria cultura por meio da compreensão da(s) cultura(s) estrangeira(s). 0 desenvolvimento da habilidade de entender/dizer o que outras pessoas, em outros países, diriam em determinadas situações leva, portanto, à compreensão tanto das culturas estrangeiras quanto da cultura materna. Essa compreensão intercultural promove, ainda, a aceitação das diferenças nas maneiras de expressão e de comportamento (BRASIL, PCN Língua Estrangeira, 1998, p. 37).

No entanto, sem diretrizes norteadoras e sem políticas públicas próprias, o ensino de Inglês para os anos iniciais do Ensino Fundamental tem carecido de pesquisas e de produções de materiais didáticos comprometidos com a formação cidadã. E mais, a falta de amparo legal não permite que o idioma faça parte do Programa Nacional do Livro Didático para esse segmento da Educação Básica. No caso da rede municipal de educação de Niterói, o material didático adotado foi elaborado por uma editora que desenvolve livros para cursos livres de línguas.

Diante de um material que não contempla a realidade socioeconômica e educacional dos alunos, além da desmotivação com o aprendizado da Língua Inglesa por conta do livro não atender às suas expectativas e aos seus interesses, propus-me a investigar a minha realidade e a minha prática. Em parceria com o Programa de Residência Docente do Colégio Pedro II, foi construído um plano de ação desenvolvido por meio de um projeto interdisciplinar que atendesse às necessidades dos alunos e às demandas sociais, que exigem o uso das habilidades de leitura e de escrita no idioma alvo. Como sou também professora dos $1^{\circ}$ e $2^{\circ}$ ciclos, contemplei as competências e objetivos desenvolvidos em Língua Materna para esse segmento da EducaçãoBásica, 


\section{RevistAleph}

além de levar em consideração a fase de aprendizagem e o nível de letramento em que se encontram esses alunos.

O campo de pesquisa, durante o ano letivo de 2015 , foi uma turma do $5^{\circ}$ ano do Ensino Fundamental, com 27 alunos, na qual atuava como regente, em uma escola municipal situada no bairro Barreto, em Niterói. A escola não possuía a infraestrutura necessária para uma educação de qualidade mas, diferente da realidade da maioria das escolas públicas, contava com um laboratório de informática com computadores para cada dois alunos, o que foi de grande valia para o desenvolvimento da pesquisa.

Sendo assim, a partir da implementação do projeto, selecionei, desenvolvi/apliquei e analisei três atividades ${ }^{26}$ que trabalham com gêneros discursivos multimodais, desenvolvendo as habilidades de leitura e escrita, com o suporte das ferramentas da Internet. Ressalto que, ao focar nessas habilidades da língua, não foram descartadas as demais, considerando que na comunicação real as competências linguísticas são integradas. Outrossim, nem todos os alunos terão a oportunidade de utilizar a habilidade oral no país, e levando em consideração as condições das escolas públicas atuais e a carga horária destinada à disciplina, seria mais relevante focar nas competências necessárias para atender às demandas sociais, como o trabalho e os estudos. Deste modo, "a leitura é a única habilidade que atende às necessidades educacionais e que o aprendiz pode usar em seu próprio meio" (MOITA LOPES, 1996, p. 131).

Todo o projeto foi permeado por jogos de reforço linguístico/discursivo e pelo input necessário para que os alunos pudessem desenvolver as habilidades da língua. Além disso, os resultados de cada atividade foram descritos em um diário reflexivo, que deram corpo a este trabalho. Dessa maneira, proponho-me a apresentar uma das atividades e os dados colhidos de maneira que possamos refletir sobre a ressignificação do ensino de Língua Inglesa nas escolas públicas brasileiras.

\footnotetext{
${ }^{26}$ Neste artigo será apresentada uma dessas três atividades.
} 


\section{RevistAleph}

\section{Cenário atual do ensino de Língua Inglesa no contexto da escola pública}

O objetivo da educação nos primeiros anos escolares é formar para a cidadania, preparando o aluno para atuar de maneira crítica e reflexiva na sociedade. Portanto, o ensino de uma Língua Estrangeira exerce um importante papel na formação discente "à medida que permite aos alunos entrar em contato com outras culturas, com modos diferentes de ver e interpretar a realidade" (BRASIL, PCN Língua Estrangeira, 1998, p. 54). Em outras palavras, a aprendizagem de outra língua possibilita o desenvolvimento da consciência crítica do aluno como cidadão e ser humano capaz de refletir sobre suas ações no mundo. Assim, com o propósito de desenvolver a cidadania e a autonomia do aluno, a Língua Estrangeira não deve ser vista como uma disciplina isolada do currículo. Todavia, de acordo com Brasil (1998, p. 15), "as disciplinas de Línguas Estrangeiras encontram-se deslocadas da escola, o que é evidenciado pela proliferação de cursos particulares. Seu ensino, porém, como o de outras disciplinas é função da escola." Os centros de línguas são, portanto, entendidos como suplementares à oferta da Língua Estrangeira dentro do currículo. Ademais, os professores tendem a organizar os conteúdos de maneira simplificada, por meio de textos e diálogos que não são autênticos, focados na exploração de palavras e estruturas gramaticais isoladas e descontextualizadas, como tentativa de facilitar a aprendizagem. Implicitamente, a posição do professor frente à capacidade dos discentes em aprender uma segunda língua influencia no processo de ensino e aprendizagem. Em seu livro 'Oficina de Linguística Aplicada', Moita Lopes (1996) cita dois autores, Rosenthal e Jacobson (1973), que chamam a ideologia da falta de aptidão de "profecia autorrealizadora". A percepção que a escola tem dos alunos em relação às suas habilidades e às suas capacidades pode determinar o seu rendimento escolar. Ainda sobre a ideologia da falta de aptidão ou capacidade, Bourdieu e Passeron (2013) defendem que a escola tem o papel de educar o aluno para a cidadania, sendo capaz de distinguir se ele está sendo vítima de violência simbólica. Em outra obra, Bourdieu explica que a violência simbólica é uma 
[...] violência suave, insensível, invisível a suas próprias vítimas, que se exerce essencialmente pelas vias puramente simbólicas da comunicação e do conhecimento, ou, mais precisamente, do desconhecimento, do reconhecimento ou, em última instância, do sentimento (BOURDIEU, 2003, p. 7-8).

Esse processo leva o aluno a enxergar seu professor como uma figura de autoridade; logo, ele legitima a sua mensagem, tornando o ato pedagógico uma prática na qual são impostos aos educandos certos valores que os predispõem a agirem de certa maneira. Sendo assim, em relação ao ensino de Língua Inglesa, a ideia que os professores carregam de que os alunos não são capazes de aprender uma Língua Estrangeira os torna inseguros e mais sujeitos a acreditarem na sua possível falta de aptidão. A esse respeito, Cruz e Rocha Lima (2014) pontuam que

O ciclo que perpetua o "fracasso" da LI na escola faz com que o professor não valorize a sua disciplina, assim como seus colegas e a direção da escola; essa atmosfera negativa consegue baixar, ainda mais, a autoestima do professor, frustrando-o. Ele não consegue (ou já não deseja mais) mudar a postura de seu aluno diante do estudo da língua, e toda essa rede de desencontros faz com que o aluno primeiro suspeite, depois acredite, e por fim, constate que ali (a escola) não é o lugar para se aprender Inglês. Triste engano (CRUZ E ROCHA LIMA, 2014, p. 196).

O material didático adotado pela rede municipal de Niterói, além de ter uma abordagem destinada a escolas de idiomas, focada no desenvolvimento das habilidades oral e auditiva, ignora as condições de nossas salas de aula, como turmas lotadas, falta de infraestrutura, carga horária reduzida destinada à disciplina e a premissa da educação no Brasil que é a formação cidadã. Segundo Moita Lopes (1996), uma ou duas horas de aula por semana não irão produzir falantes avançados numa segunda língua. Além disso, segundos os alunos que participaram do projeto, a temática do livro é infantilizada, não levando em consideração o contexto social e os seus interesses, desmotivando-os. Esse foi um dos obstáculos enfrentados na minha instituição de origem, onde a maioria dos alunos não demonstrava interesse pelas 


\section{RevistAleph}

aulas de Inglês e questionava o uso do livro didático. Frases, ${ }^{27}$ como "o livro é bobo." (aluna $\mathrm{A}$ do $5^{\circ}$ ano) e "Por que não podemos aprender Inglês através dos jogos e das músicas que a gente gosta?" (aluno B do $5^{\circ}$ ano), certamente atuaram como 'gatilhos', propiciando a reflexão sobre minha prática docente.

\section{O plano de ação}

Levando em consideração a desmotivação e a resistência dos alunos em relação ao Inglês e ao material didático em uso, a proposta foi intervir por meio de um projeto que abordasse os temas do livro, os temas transversais e os projetos desenvolvidos pela escola, trabalhando as habilidades de leitura e escrita por meio de gêneros discursivos socialmente relevantes e aqueles com que os alunos têm mais contato no meio virtual.

Esse projeto foi dividido em duas etapas, com seis unidades didáticas cada, e teve o seu início em julho de 2015. Porém, infelizmente, não foi possível realizar todas as atividades devido a diversos contratempos, como feriados, além do fato de que ocasionalmente, as aulas de Inglês eram destinadas a outros fins, como avaliações e apresentações artísticas. Sendo assim, as seis unidades didáticas desenvolvidas serão apresentadas a seguir.

A concepção (o pré-texto) do projeto se deu por meio do filme 'Tarzan', da Disney. Com a intenção de partilhar saberes e promover um ensino interdisciplinar, o filme foi o escolhido a fim de aproveitar os projetos realizados pela turma e de explorar os temas presentes. Com ele, exploramos temas como o espaço geográfico da África, os animais africanos ameaçados de extinção, a Cultura Inglesa e Africana. Ademais, foi possível desenvolver conteúdos da Língua Inglesa listados no livro didático, como nacionalidade, os animais, descrição da aparência e roupas.

\footnotetext{
${ }^{27}$ Frases retiradas das primeiras anotações do diário de campo para a construção do projeto. Foram feitas perguntas em um momento de discussão com o grupo, como: 'O que vocês acham do livro de Inglês?' e 'Como vocês gostariam de aprender Inglês?'
} 


\section{RevistAleph}

O projeto foi iniciado com o uso de uma WebQuest, ${ }^{28}$ por meio da qual ele foi apresentado, as atividades foram definidas e o processo de avaliação discutido. Segundo Dogde (1995), WebQuest é "uma atividade orientada para a pesquisa na qual algumas ou todas as informações com as quais os estudantes interagem vêm de fontes na Internet". Nesse momento, foi proposta uma atividade de sensibilização com o intuito de mostrar aos alunos que eles são capazes de ler em uma Língua Estrangeira (a atividade foi necessária diante da resistência com a Língua Inglesa), além de promover uma discussão sobre a relevância de se estudar outra língua.

Na segunda atividade, consultando a WebQuest disponibilizada no 'Google Site, ${ }^{29}$ os alunos pesquisaram e responderam a um questionário, hospedado no 'Google Formulário'30 sobre informações pessoais do Tarzan. Logo após, eles preencheram um perfil impresso com o layout do Facebook, com informações sobre o seu artista favorito. Além disso, utilizando o mapa mundi, os alunos localizaram o país do seu artista favorito e o continente Africano.

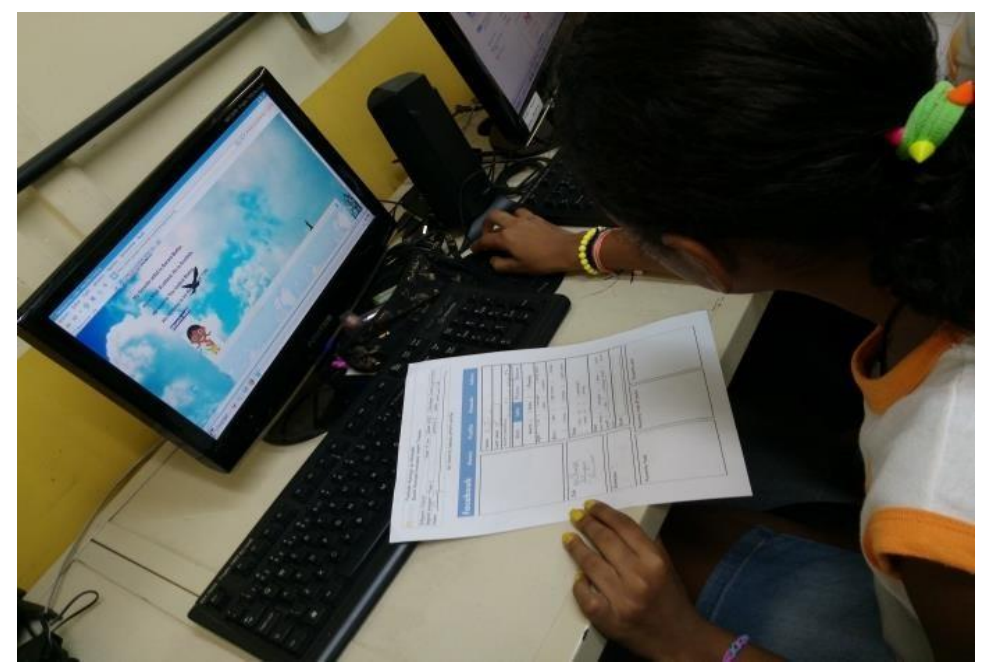

Figura 1 . Consulta webcast

Fonte: Dados de pesquisa

\footnotetext{
${ }^{28}$ Apresentação do projeto criada através da ferramenta de computador Microsoft Office PowerPoint. Disponível em:

https://drive.google.com/drive/folders/OB-RmXdlzVOFhUFVBaWFfVmQtSjA?usp=sharing .Acessado em 01 out. 2017.

${ }^{29}$ Apresentação do projeto através da ferramenta online Google sites. Disponível em $<$ https://sites.google.com/site/projectlifeempat/home>. Acessado em 25 jan. 2016.

${ }^{30}$ Google formulário. Disponível: <http://goo.gl/forms/OsuC7Z1SGR>. Acessado em 25 jan. 2016.
} 


\section{RevistAleph}

Com o gênero biografia foi possível desenvolver as habilidades de leitura e escrita, além do tópico gramatical 'verb to be', oferecendo o input necessário para que os alunos pudessem realizar as próximas atividades, concluindo assim a terceira unidade didática.

A próxima atividade, a quarta, foi a criação de uma história em quadrinhos sobre a vida do Tarzan, utilizando o site 'Pixton'. Como pré-leitura, os alunos jogaram um jogo em que tiveram que relacionar imagens da história do Tarzan com pequenas frases que as representassem, criando uma sequência cronológica. Eles também recontaram a história, completando as frases sobre cada cenário e desenhando-os.

Com a intenção de trabalhar a questão da ameaça de extinção de alguns animais africanos, principalmente os que aparecem no filme, os alunos realizaram uma atividade de compreensão leitora sobre propagandas de conscientização. Finalizando a atividade da quinta unidade, a proposta foi a criação de cartazes denunciando a caça predatória.

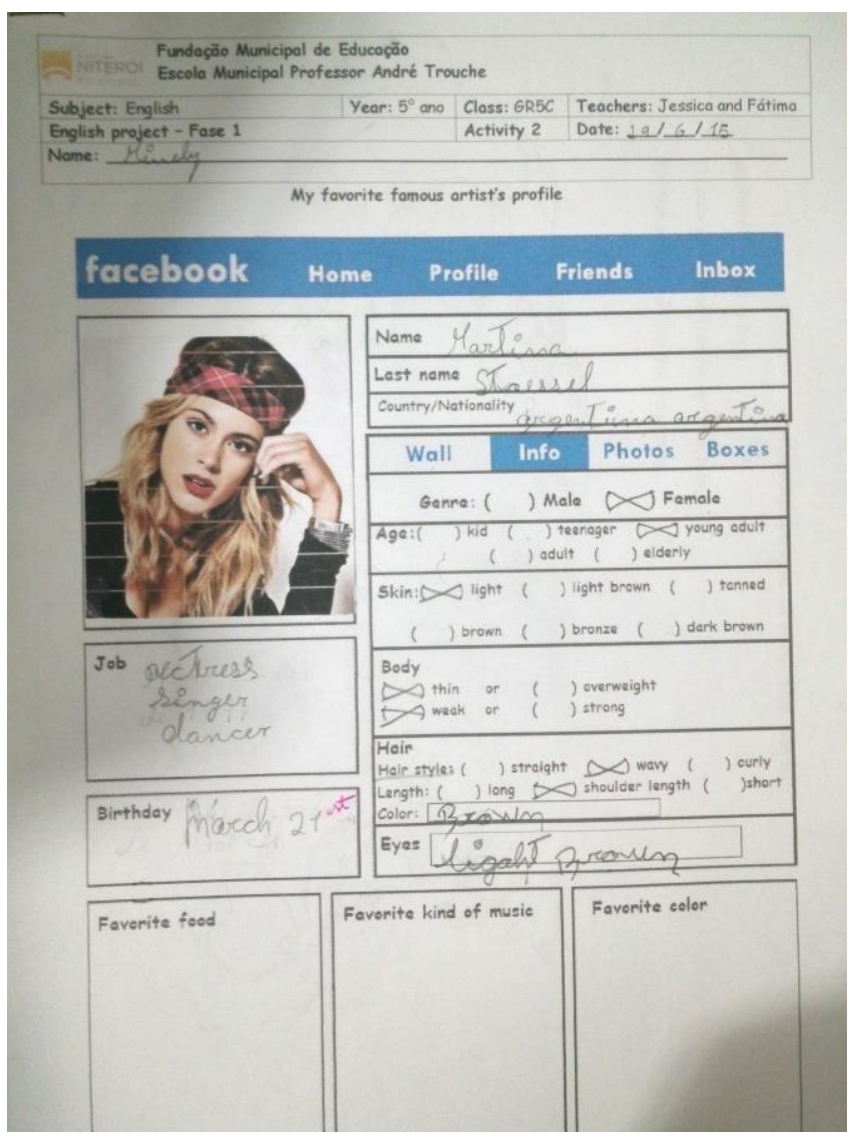

Figura 2 . Perfil Facebook

Fonte: Dados de pesquisa 


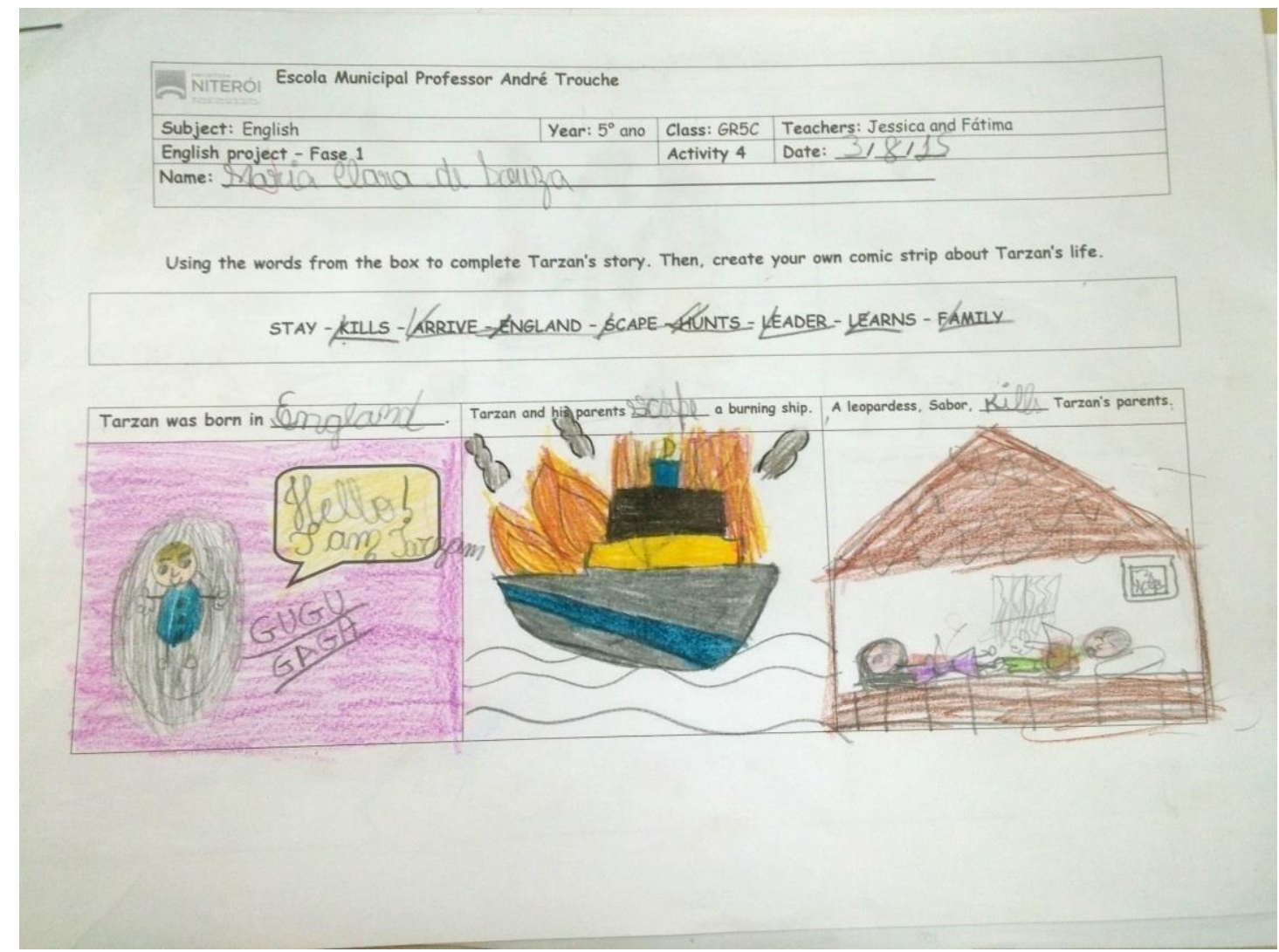

Figura 3 . História em quadrinhos

Fonte: Dados de pesquisa

Concluindo a última atividade, realizada dentro do cronograma e do ano letivo de 2015 , os alunos consultaram um site ' $W i x$ ', ${ }^{31}$ criado para guiá-los na realização da atividade. Com o objetivo de desenvolver o vocabulário sobre partes do corpo, aparência e roupas, os alunos preencheram um perfil sobre o seu artista favorito, consultando o 'Prezi'. ${ }^{32} \mathrm{~A}$ partir disso, eles responderam a um questionário criado por meio do 'Google Formulário'33 sobre a aparência física do Tarzan. Toda a atividade foi reforçada por jogos (online) de teor linguístico/discursivo.

\footnotetext{
${ }^{31}$ Wix (ferramenta online para criação de sites). Disponível em: <http://jenatarelli.wix.com/projectlife>. Acessado em 01 out. 2017.

${ }^{32}$ Prezi (apresentação do vocabulário necessário). Disponível em:

<http://prezi.com/x6gjhit6i2fx/?utm_campaign=share\&utm_medium=copy>. Acessado em 01 out. 2017. ${ }^{33}$ Google formulário. Disponível em: <https://docs.google.com/forms/d/109hli_7Xu1pHSi6pIJ_MJOXZxeZlgZMRs3vZ9aTNIU0/viewform?usp= send_form>. Acessado em 01 out. 2017.
} 


\section{RevistAleph}

Para desenvolver o vocabulário referente a roupas, primeiramente, os alunos realizaram uma atividade de compreensão leitora sobre um e-mail que enviei para a turma, oferecendo as ferramentas e os conhecimentos necessários para a atividade final da presente etapa. Então, os alunos criaram uma lista de compras com a ajuda do website 'Aliexpress', onde tiveram que comprar roupas para o Tarzan, pois ele iria visitar o seu país de origem, a Inglaterra. A partir dessa lista de compras, os discentes criaram um e-mail, descrevendo a loja e as roupas que eles gostariam de comprar.

O produto final da primeira etapa do projeto seria a criação de um blog com diferentes destinos turísticos ingleses pesquisados pelos alunos. E mais, pensou-se em uma próxima etapa para o projeto, em que, por meio do jogo para computadores 'The Sims 4', os alunos iriam criar uma personagem, revendo e reforçando o vocabulário trabalhado durante o projeto. Para essa etapa, eles iriam criar uma história em quadrinhos com a personagem, desenvolvendo assim as habilidades de leitura e escrita em Inglês com o auxílio da ludicidade.

Para fins de geração de dados, três atividades selecionadas do projeto foram analisadas após a sua aplicação. Essas atividades, cujo foco foi investigar as produções dos alunos, envolvendo as habilidades de leitura e de escrita, abrangeram gêneros discursivos, como perfil/questionário, biografia e propaganda. Ademais, as observações e os resultados obtidos durante o projeto foram apresentados por meio de um diário reflexivo, o qual contribuiu para as conjecturas sobre a experiência do trabalho com o projeto e com os respectivos gêneros desenvolvidos no $5^{\circ}$ ano de escolaridade do Ensino Fundamental.

\section{Descrição de unidade didática e resultados}

Diante das necessidades e dos interesses dos alunos, e entendendo que a língua é um meio de comunicação global, um gênero discursivo foi selecionado. Esse gênero foi escolhido levando em consideração aqueles que fazem parte do currículo de Língua Portuguesa para $05^{\circ}$ ano do Ensino Fundamental e os que os alunos já haviam 
trabalhado em sala de aula. Além da descrição da atividade, alguns resultados serão também mostrados a fim de apresentar a produção dos discentes.

\section{UNIDADE DIDÁTICA - PROPAGANDA DE CONSCIENTIZAÇÃO}

Grupo: $5^{\circ}$ ano

Data: 31 / 08 / 2015 e 14 / 09 / 2015

Tempo: 3 horas (4 tempos)

Habilidades desenvolvidas: leitura, escrita e compreensão textual.

Recursos: apresentação de slides (computador e Data show ou TV), folhas impressas de exercícios, cartolina, canetinha hidrocor, jornais, revistas, imagens da Internet, cola e tesoura.

\begin{tabular}{|c|c|}
\hline ATIVIDADE 1 & $\begin{array}{l}\text { Apresentação das propagandas (distribuição de folhas impressas) } \\
\text { (seções I e II) }\end{array}$ \\
\hline Procedimentos & $\begin{array}{l}\text { Sensibilização: exibição de apresentação do PowerPoint sobre } \\
\text { animais ameaçados de extinção. } \\
\text { Pre-reading } \\
\text { Tema: caça predatória. } \\
\text { Levantamento de questões relativas ao tema a fim de ativar o } \\
\text { conhecimento prévio; identificação do gênero discursivo, suas } \\
\text { características principais e sua finalidade; apresentação das } \\
\text { propagandas e levantamento de hipóteses sobre suas intenções; } \\
\text { reconhecimento dos possíveis significados das palavras e do assunto } \\
\text { dos textos a partir das imagens e do contexto sócio discursivo por } \\
\text { meio da estratégia de leitura predictinq. }\end{array}$ \\
\hline Tempo & 15 minutos \\
\hline ATIVIDADE 2 & Leitura do texto (seção II) \\
\hline Procedimentos & $\begin{array}{l}\text { First reading: leitura individual e silenciosa; } \\
\text { Language study: leitura compartilhada, utilizando a seção 'useful } \\
\text { vocabulary' como fonte de consulta; } \\
\text { Second reading: discussão em grupo sobre os possíveis significados } \\
\text { dos textos e suas intenções (exercício a, seção II). }\end{array}$ \\
\hline
\end{tabular}




\begin{tabular}{|c|c|}
\hline Tempo & 15 minutos \\
\hline ATIVIDADE 3 & Exercícios de compreensão leitora (seções III, IV e V (a)) \\
\hline Procedimentos & $\begin{array}{l}\text { Estabelecimento de relação entre imagem e texto; } \\
\text { Inferência de significado; } \\
\text { Realização dos exercícios propostos; } \\
\text { Correção no quadro. }\end{array}$ \\
\hline Tempo & 40 minutos \\
\hline \multirow[t]{2}{*}{ ATIVIDADE 4} & Post-reading (seção V, exercício b) \\
\hline & $\begin{array}{l}\text { - } \quad \text { Verificação das capacidades de apreciação e réplica; } \\
\text { - } \quad \text { Correção oral. }\end{array}$ \\
\hline Tempo & 10 minutos \\
\hline ATIVIDADE 5 & Tópico gramatical (seção VI) \\
\hline Procedimentos & $\begin{array}{l}\text { - } \quad \text { Sistematização da estrutura gramatical no quadro; } \\
\text { - } \quad \text { Demonstração de exemplos com o uso do texto; } \\
\text { - } \quad \text { Exercício prático e correção no quadro. }\end{array}$ \\
\hline Tempo & 30 minutos \\
\hline ATIVIDADE 6 & Produção Escrita (seção VII) \\
\hline Procedimentos & $\begin{array}{l}\text { - Elaboração de frases sobre a conscientização ambiental e a } \\
\text { caça predatória, utilizando os verbos no modo Imperativo; } \\
\text { - Correção individual. }\end{array}$ \\
\hline Tempo & 30 minutos \\
\hline AVALIAÇÃO & $\begin{array}{l}\text { Confecção de cartazes sobre a conscientização ambiental e sobre a } \\
\text { caça predatória ( } 40 \text { minutos). }\end{array}$ \\
\hline
\end{tabular}

A presente atividade foi aplicada no dia 31 de agosto, dividida em duas aulas. 0 seu principal objetivo foi desenvolver as capacidades de leitura para cidadania com o intuito de oferecer recursos para discussão e reflexão sobre questões referentes à caça predatória e à conscientização ambiental através de propagandas da WWF. ${ }^{34}$

Inicialmente, foi realizada uma apresentação em PowerPoint contendo alguns

\footnotetext{
${ }^{34}$ World Wide Fund for Nature é uma organização não governamental internacional que atua na conservação, investigação e recuperação ambiental. Website: <https://www.worldwildlife.org/>. Acessado em 01 out. 2017.

Propagandas utilizadas. Disponíveis em: <http://wwf.panda.org/?208289/Ad-campaign-aims-to-reduceVietnamese-demand-for-rhino-horn> e <https://adsoftheworld.com/media/print/tarzan_0>. Acessado em 01 out. 2017.
} 


\section{RevistAleph}

animais ameaçados de extinção ou extintos no Brasil e na África, relacionando-os aos animais africanos presentes no filme exibido no início do projeto. Logo após, eles responderam a algumas questões sobre a caça predatória e sobre animais ameaçados de extinção na África e no Brasil.

Então, iniciando a etapa de leitura, os alunos observaram as imagens e leram as propagandas presentes na atividade, silenciosamente. Em seguida, foi promovido um momento de discussão sobre essas propagandas.

Na primeira atividade de compreensão, os discentes marcaram com um $X$ as afirmativas verdadeiras em relação à intenção das propagandas apresentadas na atividade. Posteriormente, eles responderam a uma pergunta sobre a propaganda 1, estabelecendo relação entre a imagem e o texto, inferindo significado. Dando continuidade às questões de compreensão leitora, os alunos escreveram $\mathrm{V}$ para verdadeiro e $\mathrm{F}$ para falso para as afirmativas sobre a propaganda 2.

Sobre uma nova propaganda a respeito da conscientização ambiental, os alunos responderam a uma questão em que eles deveriam mencionar qual mensagem a mesma tinha a intenção de transmitir. Ainda observando essa propaganda, o grupo deveria responder acerca das consequências do desmatamento florestal, desenvolvendo a capacidade de apreciação. A esse respeito, concordo com Rojo (2004) quando a autora diz que desenvolver tal capacidade é necessário à medida que devemos elaborar

[...] apreciações relativas a valores éticos e/ou políticos: Mas também discutimos com o texto: discordamos, concordamos, criticamos suas posições e ideologias. Avaliamos os valores colocados em circulação pelo texto e destes, são especialmente importantes para a cidadania, os valores éticos e políticos. Esta capacidade é que leva a uma réplica crítica a posições assumidas pelo autor no texto (ROJO, 2004, p. 7).

Por meio de exemplos dos textos e referentes ao tema, foi introduzido o tópico gramatical 'Imperative verbs'. Antes da atividade de desenvolvimento do tópico da estrutura, a gramática foi sistematizada e explicada no quadro. Então, os alunos completaram cartazes com os Imperativos dos verbos apresentados nas formas afirmativa e negativa, oferecendo o input necessário para o desenvolvimento da 


\section{RevistAleph}

atividade escrita (pós-leitura - parte 2).

Como introdução da produção de texto, os alunos criaram frases usando verbos no Imperativo sobre questões relacionadas à caça predatória na África e aos animais ameaçados de extinção. A partir dessas frases, previamente corrigidas, com imagens de jornais, revistas ou da Internet, o grupo criou cartazes de conscientização sobre a caça predatória e a extinção dos animais no Brasil e na África.

Os alunos participaram da atividade com muito entusiasmo, apresentando a sua visão crítica sobre o tema. Ademais, eles gostaram muito da atividade por causa da confecção de cartazes, pois o grupo é consciente em relação ao meio ambiente e sempre procura manifestar a sua opinião.

Em relação às questões de compreensão leitora, alguns apresentaram um pouco de dificuldade e resistência, porém houve uma discussão anterior que os ajudou a realizar a atividade, além da apresentação do significado das palavras-chave para compreensão das propagandas. Outrossim, os alunos não demonstraram muita dificuldade em relação ao desenvolvimento da habilidade escrita na produção de frases para a confecção dos cartazes, pois eles utilizaram as que foram trabalhadas na atividade como exemplos e dicionários para consulta. Diante disso, foi perceptível o entendimento que eles tiveram em relação ao uso do Imperativo.

No decorrer da atividade, houve a utilização da Língua Portuguesa com a Língua Inglesa na produção das frases, uma etapa justificável no processo de aprendizado de uma língua adicional, uma vez que era perceptível que os alunos estavam obtendo resultados.

Sobre esse aspecto do aprendizado, Selinker (1972) diz que a interlíngua é uma estratégia criada pelo aluno que tem a intenção de aprender uma segunda língua, criando um sistema linguístico intermediário entre a Língua Materna e a língua alvo. Portanto, estruturas gramaticais e fonemas, por exemplo, da Língua Materna, são utilizados pelo aluno durante o processo de novas construções na Língua Estrangeira (língua alvo). Dessa maneira, os "erros" não são aleatórios e não podem ser vistos como algo que deve ser punido. Pelo contrário, eles são entendidos como naturais e inerentes a esse processo (CORDER, 1967). 


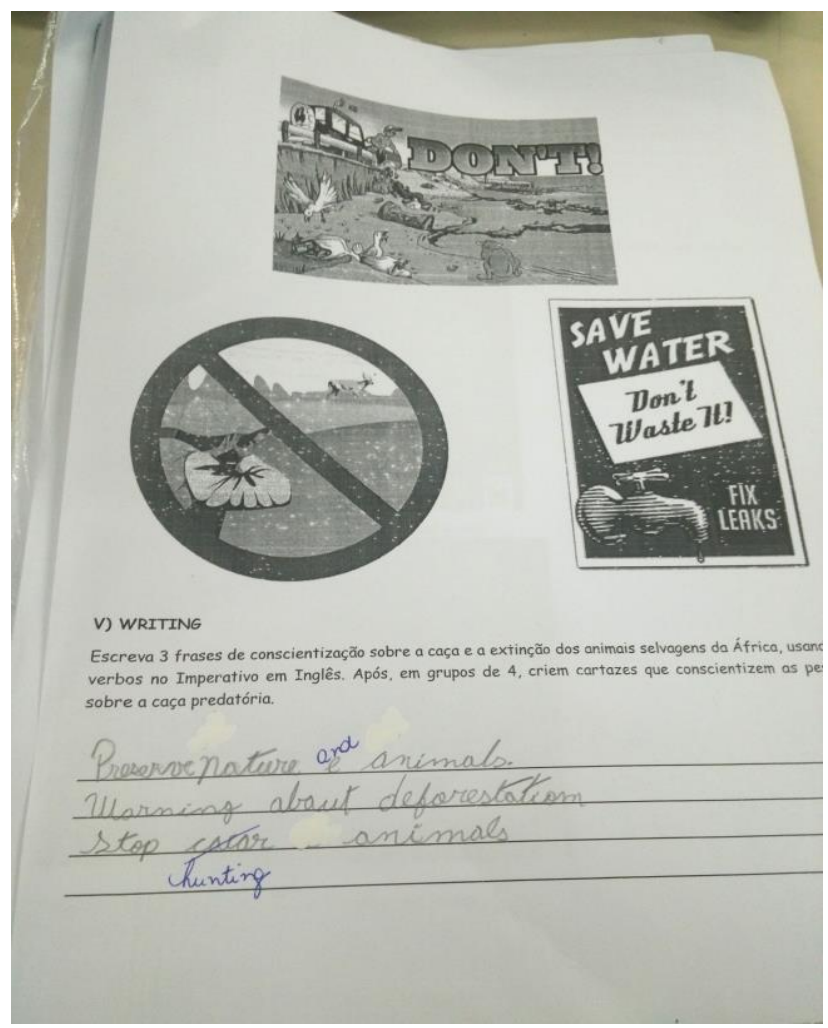

Figura 4 . Caça predatória

Fonte: Dados de pesquisa

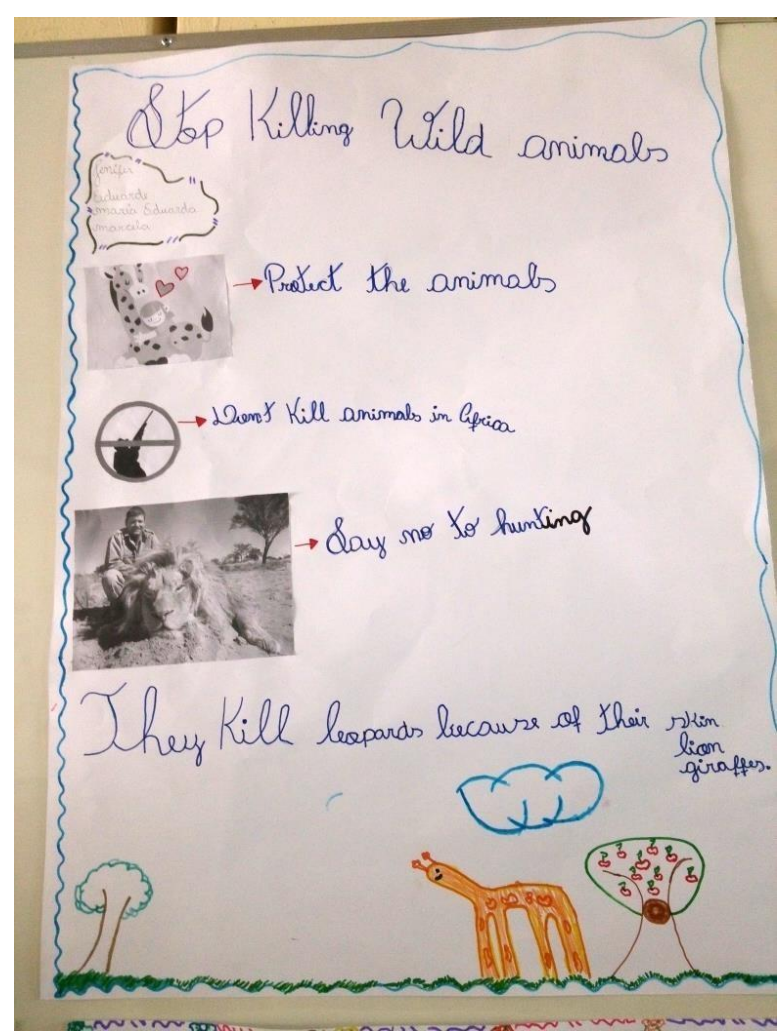

Figura 5 . Pôster

Fonte: Dados de pesquisa 


\section{A proposta: práticas de letramento e as novas tecnologias}

Diante do perfil da sociedade atual, com uma grande variedade de culturas convivendo no mesmo espaço, dialogando entre si, produzindo e reproduzindo sentidos e enunciados, materializados nos diferentes gêneros discursivos e suas configurações (letramentos multissemióticos), surgiu a necessidade de novas práticas de letramento, os multiletramentos. De acordo com Rojo (2009, p. 89),

O volume de informações, produzidas em decorrência da globalização, e das novas tecnologias, é constantemente superado, colocando novos parâmetros para a formação dos cidadãos. Não se trata de acumular conhecimentos ou de "treinar" procedimentos práticos. A formação do aluno deve ter como alvo principal a aquisição de conhecimentos básicos (ditos "competências e habilidades"), a preparação científica e a capacidade para utilizar as diferentes tecnologias relativas às áreas de atuação.

Ainda segundo a pesquisadora, os multiletramentos dizem respeito à "multiplicidade cultural das populações e a multiplicidade semiótica de constituição dos textos por meio dos quais ela se informa ou se comunica" (ROJO, 2012, p. 13). A teoria dos multiletramentos propõe valorizar os letramentos das culturas locais e de seus agentes, colocando-os em contato com as práticas de letramento eruditas e escolares. $\mathrm{E}$ mais, reconhece as diferentes configurações onde essas práticas de letramento aparecem, os letramentos multissemióticos (ROJO, 2009, p. 107). Estes referem-se ao letramento exigido pelos textos contemporâneos, como os gêneros que permeiam o meio virtual.

\footnotetext{
Assim, trata-se agora de dar conta das demandas da vida, da cidade e do trabalho numa sociedade globalizada e de alta circulação de comunicação e informação, sem perda da ética plural e democrática, por meio do fortalecimento das identidades e da tolerância às diferenças. Para tal, são requeridas uma visão situada de língua em uso, linguagens e textos e práticas didáticas plurais e multimodais, que as diferentes teorias de texto e de gênero favorecem e possibilitam (ROJO, 2009, págs. 89 e 90).
}

Ainda citando Rojo (2009), os letramentos críticos são necessários à medida que 
desenvolvem no aluno a habilidade de inferir significado aos enunciados, posicionandose criticamente, aprendendo a desvelar suas finalidades, intenções e ideologias.

Acerca do ensino de Língua Estrangeira nos anos iniciais do Ensino Fundamental, ele também é justificável à medida que "ajuda no desenvolvimento das habilidades de leitura em Língua Materna" (MOITA LOPES, 1996, p. 132). Dessa maneira, é essencial que haja uma parceria entre os professores das diferentes disciplinas que contemplam o currículo brasileiro, e assim, o Inglês assumirá o seu papel como formador de cidadãos do mundo por meio do desenvolvimento das habilidades de leitura e de escrita, que são relevantes diante do fato que

[...] os objetivos tradicionais do ensino de LE (isto é, o foco nas chamadas quatro habilidades linguísticas com ênfase nas habilidades orais) precisam ser alterados já que não têm nenhuma justificativa social no contexto brasileiro, isto é, não é apropriado. Entende que uma disciplina escolar que não é justificável socialmente não pode demonstrar, para os professores, alunos e a comunidade em geral, a necessidade de sua presença no currículo. Portanto, não deve causar surpresa o fato de os professores de LEs gozarem de muito pouco prestígio nas escolas secundárias hoje em dia (MOITA LOPES, 1996, p. 132).

Sendo assim, o ensino de uma Língua Estrangeira vai muito além da aquisição de um conjunto de habilidades linguísticas. Rojo (2004) salienta que a educação linguística deve levar em conta os objetivos da escola e o desenvolvimento das capacidades de leitura para cidadania, fazendo com que o aluno possa participar de diferentes práticas sociais que se utilizam da leitura e da escrita, os multiletramentos. Estes se materializam nos diversos gêneros de discurso - tipos de enunciados desenvolvidos a partir das esferas de atividade humana, interligadas pelo uso da língua (BAKHTIN, 2011, p. 262). Consequentemente, é por meio do trabalho com diferentes gêneros discursivos que o aluno poderá entrar em contato com a Língua Estrangeira, em um ambiente de uso real, ampliando o seu conhecimento de mundo.

Atualmente, os alunos, principalmente os da rede municipal de ensino com os quais o presente trabalho foi desenvolvido, encontram-se desmotivados com o ensino 


\section{RevistAleph}

de Língua Inglesa. Apesar de estarem em contato com a língua com o uso das músicas, dos jogos e da Internet, eles não estabelecem relação entre o Inglês da escola e o encontrado no dia a dia.

O homem usa imagens desde as cavernas e, nesse novo século, vivemos na era da informação multimídia. Imagens e sons estão em todo lugar: na vida social e nos momentos de solidão. Fotografamos todos os eventos importantes de nossas vidas, assistimos TV e DVDs, ouvimos música, etc. No entanto, a escola ainda não se apropriou adequadamente do imenso potencial desses poderosos recursos de significação [...] (PAIVA, 2007, p. 7).

Dessa maneira, o acesso que os alunos têm às novas tecnologias e as suas possibilidades de comunicação nos leva a repensar o processo de ensino e aprendizagem de Língua Estrangeira dentro do contexto escolar. Paiva (2007) salienta que os gêneros discursivos que permeiam o meio virtual conectam diferentes textos multimodais produzindo diferentes enunciados e significados.

O uso da Internet e de suas ferramentas em sala de aula propicia um trabalho mais dinâmico, interativo, cooperativo, autônomo e possibilita a publicação. Schneiderman (2003) afirma que a velha educação enfatizava a competição e que a nova educação enfatiza colaboração. A utilização do meio virtual no processo de ensino e aprendizagem favorece o trabalho colaborativo por meio também de atividades em grupos, pois de acordo com Paiva (2006), o contexto de aprendizagem da Internet é descentralizado, ou seja, professores e alunos não são detentores do saber. Eles trocam saberes e informações por meio de uma rede de comunicação global onde "os alunos estão interconectados com outros alunos com diferentes graus de autonomia e todos eles têm acesso a inúmeros recursos" (PAIVA, 2006, p. 117). Em outras palavras, a Internet amplia o leque de informações e dinamiza o acesso a elas, tornando o aluno um ser autônomo no processo de ensino e aprendizagem.

O texto no papel é escrito e é lido linearmente, sequencialmente - da esquerda para a direita, de cima para baixo, uma página após a outra; o texto na tela - o hipertexto - é escrito e é lido de forma multilinear, multi-sequencial, acionando-se links ou nós que vão trazendo telas numa multiplicidade de possibilidades, sem que haja uma ordem 


\section{RevistAleph}

predefinida (SOARES, 2002, p. 151).

E, com o auxílio dos hipertextos, o aluno é capaz de fazer suas próprias escolhas.

As práticas de leitura e escrita no hipertexto revolucionaram até mesmo a postura física do leitor. Antes, com possibilidades limitadas de consultar simultaneamente os materiais de leitura e exercer a produção da escrita, hoje encontrar um espaço de leitura e escrita totalmente maleável; a estrutura de interação, a plasticidade de abrir janelas e caixas de textos concomitantemente, os recursos de formatação e fragmentação da informação, entre outros, definem um novo estilo de comportamento seja do leitor e/ou escritor (ARAÚJO, 2008, p. 7).

Para mais, a Internet disponibiliza meios, ambientes e ferramentas de produção textual e de publicações que ultrapassam os muros da escola, onde as produções dos alunos vão além da relação aluno-professor, tendo um público autêntico como leitor. Além de atribuir sentido às produções textuais dos alunos, "a publicação pode trazer acréscimos à autoestima e à construção da autoria, além de motivar os produtores de textos a escreverem de maneira mais significativa" (SOUZA, 2008, p. 30).

Destarte, novos letramentos requerem o desenvolvimento de novas habilidades e competências diante do que fato de que nossos alunos estão expostos, no ambiente virtual, a diferentes enunciados repletos de diferentes valores, éticas e ideologias.

O crescente aumento na utilização das novas ferramentas tecnológicas (computador, Internet, cartão magnético, caixa eletrônico etc.) na vida social tem exigido dos cidadãos a aprendizagem de comportamentos e raciocínios específicos. Por essa razão, alguns estudiosos começam a falar no surgimento de um novo tipo, paradigma ou modalidade de letramento, que têm chamado de letramento digital. Esse novo letramento, segundo eles, considera a necessidade dos indivíduos dominarem um conjunto de informações e habilidades mentais que devem ser trabalhadas com urgência pelas instituições de ensino, a fim de capacitar o mais rápido possível os alunos a viverem como verdadeiros cidadãos neste novo milênio cada vez mais cercado por máquinas eletrônicas e digitais (XAVIER, 2005, p. 1).

Cabe à escola disponibilizar as ferramentas de leitura necessárias para que os 
alunos possam fazer suas escolhas conscientes do significado que esses enunciados carregam. Portanto, isso significa educá-los para a era digital: “[...] é preciso ser letrado digital, isto é, fazer-se cidadão do mundo também através dos processos digitais, hoje um pouco mais democraticamente disponíveis" (XAVIER, 2005, p. 8).

\section{Reflexões finais}

Apesar da crescente demanda e expansão do ensino da Língua Inglesa nas redes municipais de ensino, muito pouco tem se investido na área em relação aos $1^{\circ}$ e $2^{\circ}$ ciclos do Ensino Fundamental. Dessa maneira, surge um cenário de desmotivação, tendo como pano de fundo a atual conjuntura do processo de ensino e aprendizagem da língua. Soma-se ainda o fato de que as diretrizes que norteiam o seu ensino e o material didático em uso na rede municipal de Niterói não contemplam os interesses dos alunos e a demanda de um mundo globalizado.

A investigação aqui apresentada foi um caminho que promoveu mudanças na minha prática docente, pois pude constatar que as aulas de Língua Inglesa podem ir além do 'verb to be', proporcionando aos alunos um ensino mais significativo, dinâmico e desenvolvendo as habilidades linguísticas necessárias para eles possam se tornar cidadãos do mundo. De acordo com Cruz (2005), a tarefa do professor é propiciar ao aluno uma aprendizagem relevante que se conecte a conceitos prévios, que atenda às suas necessidades e que contemple a sua realidade, evitando assim, a memorização e a repetição de estruturas da língua.

Diante do contexto da minha instituição de origem, este trabalho forneceu as ferramentas para que fosse possível investigar caminhos a fim de superar os desafios do ensino de Inglês no contexto da escola pública, particularmente no que se refere ao material didático, intervindo com atividades que desenvolveram a habilidade de leitura por meio de um trabalho crítico com a linguagem. Portanto, acredito que o objetivo deste trabalho foi alcançado, ao propor a reflexão a respeito do ensino do Inglês para os anos iniciais do Ensino Fundamental, sugerindo caminhos para que possamos buscar 


\section{RevistAleph}

a ressignificação do ensino do idioma com o intuito de projetar experiências de aprendizagem mais significativas e interessantes.

\section{REFERÊNCIAS}

ARAÚJO, Rosana Sarita. Letramento digital: conceitos e preconceitos. Anais eletrônicos do 2ㅇ. Simpósio Hipertexto e tecnologias na educação: multimodalidade e ensino. 1ạ edição. 2008. UFPE. Disponível em: <http://www.ufpe.br/nehte/simposio2008/anais/Rosana-SaritaAraujo.pdf $>$. Acesso em: 17 out. 2015.

BAKHTIN, Mikhail. Estética da Criação Verbal. 6 ed. São Paulo: Martins Fontes, 2011.

BOURDIEU, Pierre. A dominação masculina. 3 ed. Rio de Janeiro: Bertrand Brasil, 2003.

BOURDIEU, Pierre; PASSERON, Jean-Claude. A Reprodução: Elementos para uma Teoria do Sistema de Ensino. 6 ed. Petrópolis, RJ: Vozes, 2013.

BRASIL. Lei de Diretrizes e Bases da Educação Nacional. Lei Federal n 9.394 de 20 de dezembro de 1996 estabelece as Diretrizes e Bases da Educação Nacional. Brasília: 1996.

BRASIL. MEC. Secretaria de Educação Fundamental. Parâmetros curriculares nacionais: terceiro e quarto ciclos do ensino fundamental: língua estrangeira. Brasília: MEC/SEF, 1998.

CORDER, Stephen Pit. The significance of learner errors. International Review of Applied Linguistics, vol. v/4, p. 161-169, nov. 1967. Disponível em: <http://www.uky.edu/ tmclay/Corder\%201967.pdf>. Acesso em: 22 de nov. 2015.

CRUZ, Giêdra Ferreira da. A contribuição das estratégias metacognitivas para 0 desenvolvimento da autonomia do aprendiz. Mestrado em Letras. Salvador: Instituto de Letras da Universidade Federal da Bahia, 2005.

CRUZ, Giêdra Ferreira da.; ROCHA LIMA, Joceli. Quem faz o ensino de inglês na escola (não) funcionar? In: LIMA, Diógenes Candido de. (Org.). Inglês em escola pública não funciona? Uma questão de múltiplos olhares. São Paulo: Parábola, p. 185-196, 2014.

DODGE, Bernie. Some Thoughts About WebQuests. 1995. Disponível em: <http://edweb.sdsu.edu/courses/EDTEC596/About_WebQuests.html> Acesso em: 01 out. 2017.

MOITA LOPES, Luiz Paulo da. Oficina de Linguística Aplicada. Campinas, SP: Mercado de Letras, 1996.

PAIVA, Vera Lúcia Menezes de Oliveira e. Autonomia e complexidade. Linguagem e ensino, vol. 9, no 1, p. 77-127, jan./jun. 2006. Disponível em: <http://www.rle.ucpel.tche.br/index.php/rle/article/view/176>. Acesso em: 12 de dez. 2015. 


\section{RevistAleph}

Letramento digital através de narrativas de aprendizagem de Língua

Inglesa. Crop, v. 12, p. 1-20, 2007. Disponível em: <http://www.veramenezes.com/crop.pdf>. Acesso em: 17 nov. 2015.

PENNYCOOK, Alastair. English and the discourse of colonialism. London: Routledge, 1998.

ROJO, Roxane. Letramentos múltiplos, escola e inclusão social. São Paulo: Parábola,

2009.

. Letramento e capacidades de leitura para a cidadania. São Paulo: SEE: CENP, 2004. Texto apresentado em Congresso realizado em maio de 2004. Disponível em:

<https://docgo.org/letramento-e-capacidades-de-leitura-para-a-cidadania-roxane-rojo>.

Acesso em: 29 set. 2017.

ROJO, Roxane; ALMEIDA, Eduardo de Moura (Orgs.). Multiletramentos na escola. São Paulo:

Parábola Editorial, 2012.

SELINKER, Larry. Interlanguage. International Review of Applied Linguistics, Heidelberg, v.10, p. 209-231, jan. 1972.

SHNEIDERMAN, Ben. Leonardo's Laptop: Human Needs and the New Computing Technologies.

Cambridge, MA: MIT Press, 2003.

SOARES, Magda. Novas práticas de leitura e escrita: letramento na cibercultura. Educ. Soc.

Campinas, vol. 23, n. 81, p. 143-160, dez. 2002. Disponível em: <http://www.cedes.unicamp.br>. Acesso em: 10 out. 2015.

SOUZA, Patrícia Nora de. A hipermídia como uma ferramenta de ensino: uma revisão da literatura sobre o aprendizado implícito e explícito de vocabulário em língua estrangeira. Linguagem \& Ensino, Pelotas, v.11, n.1, p. 101-124, jan./jun. 2008. Disponível em:

<http://www.rle.ucpel.tche.br/index.php/rle/article/view/128/97>. Acesso em: 12 de jan. 2016.

XAVIER, Antônio Carlos dos Santos. Letramento digital e ensino. In: SANTOS, Carmi Ferraz; MENDONÇA, Márcia (Orgs.). Alfabetização e letramento: conceitos e relações. Belo Horizonte: Autêntica, p. 133-148, 2005. 